\title{
Uma Ferramenta de Mineração de Texto para Apoio à Leitura e Escrita Autoral
}

\section{A Text Mining Tool to Support Reading and Authorial Writing}

\author{
ALEXANDRA LORANDI MACEDO \\ Universidade Federal do Rio Grande do Sul \\ FRANCIELI LUÍSA GRACIOLI \\ Universidade Federal do Rio Grande do Sul \\ ELISEO BERNI REATEGUI \\ Universidade Federal do Rio Grande do Sul \\ PATRICIA ALEJ ANDRA BEHAR \\ Universidade Federal do Rio Grande do Sul \\ VINICIUS HARTMANN FERREIRA \\ Universidade Federal do Rio Grande do Sul
}

\begin{abstract}
Resumo: Este artigo apresenta um estudo sobre o potencial de uma ferramenta de mineração de texto para auxiliar no processo de leitura e escrita autoral. No mundo letrado, a leitura e escrita estão diretamente ligadas aos processos de aprendizagem, favorecendo a formação do pensamento crítico e argumentativo. Dados estatísticos mostram que em países em desenvolvimento, como o Brasil, os estudantes demonstram grande dificuldade em escrever ou interpretar textos. Visando minimizar tais dificuldades, este estudo apresenta uma proposta que alia práticas pedagógicas e recursos tecnológicos para contribuir com os processos de leitura e escrita. O artigo apresenta um estudo envolvendo 22 estudantes que participaram de atividades de leitura e escrita em um curso semi-presencial de 30 horas. Os resultados do estudo, realizado por uma perspectiva qualitativa, permitiram concluir que as ferramentas e estratégias propostas contribuíram para o desenvolvimento de uma escrita autoral pelos participantes.
\end{abstract}

Palavras-chave: Leitura. Escrita. Autoria. Aprendizagem. Mineração de texto.

Abstract: This article presents a study on the potential of a text mining tool to assist students in reading and writing. In the literate world, reading and writing are directly linked to learning processes, favoring the development of critical and argumentative thinking. Statistics show that in developing countries, such as Brazil, students show great difficulty writing or interpreting texts. In order to minimize these difficulties, this study presents a proposal that combines teaching practices and technology to contribute to the processes of reading and writing. The article presents a study in which 22 students participated in reading and writing activities, in a 30 hours course. The results of the study, based on a qualitative perspective, allowed us to conclude that the tools and strategies proposed contributed to the development of an authorial presence in their writing.

Keywords: Reading. Writing. Authorship. Learning. Text mining.

MACEDO, Alexandra Lorandi et al. Uma Ferramenta de Mineração de Texto para Apoio à Leitura e Escrita Autoral. Informática na Educação: teoria \& prática, Porto Alegre, v. 19, n. 2, p. 123-139, jun./set. 2016. 


\section{I ntrodução}

Leitura e escrita são habilidades fundamentais em nossa sociedade, alicerçando todo o processo de aprendizagem escolar. Sabe-se que, no mundo letrado, a leitura está diretamente ligada aos processos de aprendizagem, favorecendo a formação do pensamento crítico e do poder argumentativo.

No que diz respeito à escrita, Jenner (2003) destaca a necessidade de os indivíduos serem capazes de utilizar a linguagem oral e escrita para demonstrar sua compreensão do mundo em nossa sociedade contemporânea. Warschauer (2006) também enfatiza a importância de trabalhar com os estudantes a capacidade de dar significado aos textos com base na própria experiência, a habilidade de usá-los de maneira funcional, analisá-los e transformá-los de maneira crítica.

Tratando-se de leitura e escrita, tem-se relacionado o conceito de letramento. Neste estudo, esse conceito é entendido como a apropriação das técnicas para alfabetização, além dos aspectos de convívio e o hábito da leitura e da escrita (SOARES, 1998). Isto é, ser letrado não é apenas saber assinar o próprio nome ou elaborar pequenos textos. O letramento remete para o uso eficiente da língua e a utilização desta como forma de comunicação e expressão apoiada na perspectiva autoral.

Um relatório da UNESCO sobre a avaliação de estudantes na América Latina e Caribe (SERCE, 2008) apontou que 25,5\% dos estudantes de 4 o ano possuem habilidades de compreensão leitora mínimas, sendo apenas capazes de localizar informações, com significado único, que se encontram repetidas em um texto e isoladas de outras informações. Um percentual de 6,7\% encontra-se abaixo desta faixa, não alcançando nem mesmo estas habilidades mínimas. Dados do Programme for International Student Assessment (OECD, 2012) reforçam tais resultados, indicando grande dificuldade dos estudantes brasileiros em escrever ou interpretar textos.

Assim, fazem-se necessárias ações que visem o aprimoramento do processo de leitura e escrita. A fim de atender essa demanda, o presente estudo alia práticas pedagógicas e recursos tecnológicos que têm por objetivo proporcionar o desenvolvimento dos elementos supracitados. Em decorrência disso, este artigo trata de práticas pedagógicas que utilizam a tecnologia, em especial, a mineração de texto, para potencializar o desenvolvimento ou o aprimoramento da leitura e escrita autoral. Para tanto, apresenta pesquisas relacionadas a este estudo, bem como a perspectiva teórica que define o conceito de leitura, de escrita e suas inter-relações com autoria. A intenção é mostrar a perspectiva de cada conceito, bem como aplicações práticas em contextos reais de educação.

Vale destacar que esse conjunto de elementos foi trabalhado na forma de cursos de extensão. O objetivo foi analisar estratégias pedagógicas, apoiadas na tecnologia de mineração de texto, neste caso, com o uso da ferramenta Sobek, a fim de obter indicadores sobre os processos de letramento e autoria. Os resultados foram analisados a partir de categorias que caracterizaram os elementos aqui destacados, a saber: autoria e letramento. 
A próxima seção apresenta o conceito de leitura, escrita e autoria, e também descreve uma ferramenta tecnológica específica que pode apoiar estes processos. Em seguida, a seção 3 apresenta estudos relacionados que tratam do desenvolvimento da leitura e da escrita apoiadas pela a tecnologia. A seção 4 descreve a pesquisa desenvolvida, apresentando objetivos, público-alvo, ferramentas e metodologia e segue com a análise dos dados coletados. Por fim, a seção 5 trata das conclusões.

\section{Leitura, Escrita e Autoria}

O foco deste estudo está em proporcionar condições para o aprimoramento da leitura e escrita autoral tendo como suporte a tecnologia de mineração de texto. Nesse sentido, faz-se necessário abordar aspectos teóricos da leitura e de escrita e suas inter-relações com autoria, mostrando as perspectivas de cada termo, assim como, uma visão de estratégia para suas aplicações práticas. Em seguida, a relação destes elementos com a tecnologia de mineração de texto é apresentada.

\subsection{Um Olhar Sobre Escrita: um processo, um resultado}

Nas duas últimas décadas, pesquisadores da área de Linguística Textual e da Análise do Discurso têm-se dedicado à investigação do texto como unidade de análise na linguagem. As diferentes óticas adotadas pelos pesquisadores possibilitam o surgimento de várias acepções para o termo texto. Neste trabalho, interessa a visão de texto como um conjunto de possibilidades de sentido que são reveladas conforme a atuação do leitor (POSSENTI, 2001).

Bronckart (1999) chama de texto toda unidade de produção de linguagem. Assim, texto pode ser considerado o produto do processo comunicativo que, para ser reconhecido, deve seguir determinados princípios que garantam a construção de sentido em uma determinada situação comunicativa ou contexto. Bakhtin (2001) afirma que o texto é uma construção de signos criada por um indivíduo para expressar suas opiniões, valores e crenças, resultantes da sua interação com outros indivíduos, inseridos em uma cultura e dentro de um período histórico. Se esse ser social se expressa por meio do texto que produz, deseja também que alguém o compreenda.

Para Marcuschi e Xavier (2005) a produção textual se assemelha a um jogo, pois antes de iniciar, temos de conhecer algumas regras, o espaço onde vai acontecer, qual o papel e função dos atores envolvidos. Além disso, é necessário preocupar-se também com o sucesso dos objetivos da produção textual, como a interação entre o produtor e o seu receptor. Este deverá seguir as marcas expressas no texto e aprofundar-Ihes o significado para realizar uma leitura singular, conforme Rizzo (1986). Desta forma, faz-se necessário revisar também a ação que se pratica sobre o texto, qual seja, a leitura.

\subsection{Leitura: um fenômeno complexo}

Ao analisar o processo de leitura, Kleiman afirma que 
[...] o mero passar de olhos pela linha não é leitura, pois ela implica uma atividade de procura, por parte do leitor, no seu passado de lembranças e conhecimentos, daquilo que é relevante para a compreensão de um texto, que fornece pistas e sugere caminhos, mas que não explicita tudo o que seria possível explicitar [...] (KLEIMAN, 1989, p. 27).

A leitura é um fenômeno complexo que proporciona possibilidades variadas de entendimento da relação sujeito-sociedade. Essa não se limita apenas à decifração de alguns sinais gráficos. É muito mais do que isso, visto que exige do indivíduo participação ativa no processo, levando-o à produção de sentido e à construção do conhecimento, sendo, portanto, a compreensão do texto resultado da interação entre autor e o leitor.

Anderson e Pearson (1998) pontuam o termo schema como o conhecimento que o indivíduo carrega consigo, organizado em padrões inter-relacionados e construídos por meio de experiências prévias, guiam-no à medida que faz sentido em novas experiências. Dessa forma, quando uma pessoa diz ter compreendido um texto, na realidade, ela modificou o seu espaço mental para acomodar uma nova informação: é a interação da informação nova com a antiga que é responsável pela compreensão de um texto. Além disso, quando se aborda o termo leitura, não se pode deixar dissociado do termo letramento que surgiu da necessidade de se distinguir o estado de quem sabe ler e escrever daquele que é considerado apenas alfabetizado. Em uma visão contemporânea de sociedade, espera-se que indivíduos letrados possam se expressar tanto de maneira oral quanto escrita, sendo capazes de se comunicar, de participar na resolução de problemas e na tomada de decisão (JENNER, 2003).

A atividade do leitor sobre os textos para compor seu próprio texto remete-nos ao conceito de autoria, já que autor é aquele que compõe a ideia, seja por meio da criação, seja da recriação na leitura.

\subsection{Autoria: um processo de criação e recriação da leitura}

Castells (1999) afirma que, para o conhecimento ser significativo, ele deve partir de informações relevantes que possam ser relacionadas com os conceitos pré-existentes na estrutura cognitiva do aluno. Sendo assim, defendemos que a leitura deve ser de caráter autoral, ou melhor, seu processo de construção deve partir da singularidade de seu leitor. Tal noção de leitura autoral há muito é discutida. Para Orlandi (1988), o sujeito faz-se autor quando o seu dizer constitui parte da história, ou seja, mesmo recorrendo a um já dito, a autoria se instaura quando o sujeito produz um lugar de interpretação em meio a tantos outros. Assim, muitas vezes, o entendimento do texto é mais do que uma repetição do já dito: ele está perpassado por um discurso no qual o sujeito está inserido. Na percepção de Possenti (2001), o autor constitui-se quando assume as atitudes de dar voz a outros enunciadores e também a de afastar-se do próprio texto. Uma compreensão de autoria como um gesto de individuação do sujeito, num certo lugar discursivo, requer que se leve em consideração a indissociabilidade entre o que é falado/escrito e uma memória discursiva na qual o que é falado/escrito se ancora. Assim, uma das exigências básicas para que o texto seja um texto é, necessariamente, a sua relação com outros discursos (passados e futuros). 
Um ponto importante para a visão da autoria é o Paradigma Indiciário de Ginzburg (1980). Para ele, há sinais no texto que indicam conteúdos implicitamente. As marcas são pistas que, se por um lado atestam a relação entre o sujeito e a linguagem no texto, por outro lado, não são detectadas nem apreendidas mecânica e empiricamente. Afinal, os mecanismos enunciativos, conforme diz Orlandi (1988), não são unívocos nem auto evidentes, são construções discursivas. Tais construções encontram-se constantemente em movimento, numa busca (mesmo que ilusória) da completude. Neste movimento o sujeito se constitui autor, produzindo o que Pêcheux (1995) chama de unicidade imaginária do sujeito, na qual ocorre uma identificação do sujeito do discurso com a forma-sujeito da formação discursiva. Tfouni e Bartijotto complementam que

[...] esse sujeito supõe que a escrita o leva à abstração e ao metaconhecimento; pelos efeitos ideológicos, no sentido de que a escrita fortalece a ilusão de completude [...]. O discurso da escrita possibilita ao autor a ilusão da materialidade do pensamento, visto que a escolha da palavra aparece como sendo a única possível capaz de dizer aquilo que se quer dizer [...] (TFOUNI; BARTIJOTTO, 2015, p. 142).

Apesar de saber-se quão complexas e singulares a leitura e a escrita podem ser, Assolini (2003) mostra que o discurso pedagógico escolar tradicional busca sempre a homogeneização. Sendo assim, não considera que os sentidos estão inseridos em formações discursivas e também não considera a possibilidade de existir a diversidade de leituras (interpretações) provenientes de formações discursivas diferentes. Dessa forma, no ensino da leitura, na maior parte dos casos, o aluno não pode se direcionar para outra região de sentido e arriscar-se a produzir sentidos que não sejam aqueles já cristalizados e legitimados. Ou seja, o texto, ao invés de tornar-se o primeiro passo para o reconhecimento do mundo, torna-se, por meio de suas palavras, um limitador do crescimento do aluno.

Em suma, é um desafio educacional almejar o ensino de todas as possibilidades que o texto traz, tanto para o desenvolvimento, como para a sua compreensão. Apesar disso, existem recursos tecnológicos, ferramentas que podem apoiar aluno e professor. Neste estudo, buscouse investigar de que maneira a ferramenta de mineração de texto Sobek (apresentada na próxima seção) pode potencializar o ensino da escrita e da leitura autoral.

\subsection{Sobek: ferramenta para mineração de texto}

Para implementar ações que possam potencializar e qualificar o processo de leitura e escrita autoral, este trabalho propõe o emprego da ferramenta de mineração de texto Sobek ${ }^{1}$, uma ferramenta que utiliza um método estatístico para identificar os conceitos mais relevantes de um texto (REATEGUI et al., 2011). Em razão de seu uso, é possível identificar os conceitos e as principais contribuições de cada texto. O resultado da mineração do texto pela ferramenta é um grafo de palavras no qual se destacam aquelas com maior ocorrência. Durante o processo de mineração, um conjunto de termos chamado de Stopwords é utilizado para remover do

\footnotetext{
${ }^{1}$ Ferramenta disponível em: http://sobek.ufrgs.br.
} 
texto palavras que carregam pouco conteúdo informacional, como artigos, preposições, conjunções, entre outras (MAKREHCHI; KAMEL, 2008). O processo de stemming é posteriormente realizado para que uma mesma palavra não apareça mais de uma vez no grafo, por exemplo, um mesmo verbo em diferentes conjugações.

Conceitos podem ser palavras simples (como ocorre na maioria dos casos), mas também podem ser um conjunto de palavras que têm um significado associado. Por exemplo, as palavras meio e ambiente podem ser conceitos, mas também o termo meio ambiente pode ser um conceito. O grafo resultante da mineração de um texto utiliza conceitos como nodos e a relação entre eles como arestas. Os conceitos mais frequentes no texto são apresentados no grafo em quadros com um tamanho maior. Em geral, também serão os nodos que apresentarão o maior número de conexões. Elas representam uma relação entre dois conceitos que é medida pelo número de vezes que um conceito aparece próximo ao outro no texto. Conceitos que têm maior frequência (e, portanto, devem ser considerados os principais), terão um maior número de ligações possíveis.

Tecnologicamente, a ferramenta exige o uso de um computador com configuração simples para minerar textos em diversos formatos (txt, doc, pdf), possibilitando seu uso efetivo em situações escolares. Além disso, traz a construção do grafo e a leitura de imagem como ferramenta pedagógica que proporciona uma prática de leitura e escrita diferente, mais estruturada e interativa. Do ponto de vista de construção de significado, ao trazer para o aluno uma representação não-linear do texto, a ferramenta abre a possibilidade de múltiplas leituras e interpretações.

A escolha da ferramenta Sobek para realização deste estudo está apoiada no fato de já ter sido utilizada em outros estudos, como em Reategui, Klemann e Finco (2012) e Macedo (2010). O primeiro propôs o uso da ferramenta como apoio à produção textual, mais especificamente sua possibilidade de utilização em atividades de sumarização de textos. Em Macedo (2010) verificou-se que a ferramenta pode ser utilizada pelo professor para identificar a qualidade na produção escrita dos estudantes. Os resultados demonstraram que os grafos extraídos pela ferramenta têm estreita relação com a estrutura e o conteúdo qualitativos desenvolvidos nos textos dos alunos.

Diante disso, o presente estudo buscou investigar de que forma a ferramenta Sobek poderia contribuir para o desenvolvimento da leitura e da escrita autoral.

\section{Estudos Relacionados}

Esta seção apresenta pesquisas e práticas que tratam do desenvolvimento da leitura e da escrita apoiadas pela a tecnologia. Muitas propostas têm surgido nos últimos anos para apoio às atividades de leitura e escrita. Por exemplo, Wei et al. (2012) desenvolveram uma ferramenta que integra diferentes estratégias de leitura em um sistema de e-book, demonstrando como a compreensão de leitura pode ser melhorada por meio do emprego da ferramenta. Villalón et al. (2008) implementaram um editor de texto que busca instigar a reflexão por meio do questionamento sobre o conteúdo do texto, sua estrutura e coerência. Tais propostas diferem do projeto aqui apresentado, tanto no que diz respeito aos tipos de 
tecnologia utilizados, quanto em relação às estratégias pedagógicas para seu emprego. Em nossa abordagem, o uso destas ferramentas busca empregar a noção de acoplamento tecnológico definida por Maraschin e Axt (2005). Tal perspectiva apresenta-se como um processo de apropriação que se concretiza a partir das práticas, nas quais a representação gráfica do texto de maneira não linear pode facilitar o processo de reflexão e compreensão (CHANG; SUNG, 2002).

Luu e Freeman (2011) analisaram a importância da Tecnologia da Informação e Comunicação (TIC) para o letramento, por consequência de ter sido estabelecida como fator determinante para redução de desigualdade e desenvolvimento econômico. A pesquisa foi realizada na Austrália e na Nova Zelândia, países que possuem pontuação semelhante na área da educação, conforme (OECD, 2006). A análise foi realizada por meio de questionários sobre a frequência e os lugares de uso desta tecnologia. Seus resultados comprovaram que estudantes com maior frequência de acesso apresentaram alto nível de letramento em ambos os países. Tal resultado destaca a relevância do uso de tecnologias da informação como alternativa para a promoção do letramento. A principal distinção entre o estudo realizado e a pesquisa aqui proposta está nas diferenças entre as ferramentas empregadas e práticas desenvolvidas, sendo nossa proposta focada na utilização de tecnologia de mineração de texto.

Em relação à aplicação da tecnologia de informação em sala de aula, Ferrer, Belvís e Pàmies (2011) acompanharam a implementação de tablets em escolas públicas na região de Aragon, Espanha. O objetivo era investigar as intervenções na qualidade de ensino. Para isso, foram aplicados questionários aos supervisores, aos professores, aos familiares e aos alunos; assim como a observação de aulas foi realizada. Os resultados comprovaram a influência positiva da tecnologia em núcleos familiares menos favorecidos financeiramente.

De forma mais restrita, Petko (2012) procurou esclarecer como o professor emprega a TIC em sala de aula, considerando três pontos: a competência, a crença e a ferramenta. A pesquisa foi realizada em escolas de Ensino Médio na Suíça e ocorreu por meio de questionário virtual acerca de nível de domínio de ferramentas tecnológicas, das crenças do professor em relação aos benefícios desse uso e de recursos utilizados. Os resultados demonstraram que professores que são titulares de turma, professores mais criativos ou mais seguros no emprego da tecnologia da informação a utilizam mais. Indisciplina e quantidade pequena de computadores são causas para sua recusa. Tal conclusão aponta para a importância de se trabalhar com tecnologias de fácil utilização.

Também nesse sentido, Ponce, López e Mayer (2012) avaliaram o impacto de uma ferramenta tecnológica, chamada E-PELS, sobre o desenvolvimento da leitura e sua eficiência em relação aos métodos tradicionais. A pesquisa propunha os seguintes passos de uso: leitura de pequeno texto, construção de resumo para cada tópico a partir de ideias principais, estudo de gênero e descrição do objetivo do texto. A pesquisa foi realizada em escolas da Região Central do Chile. A coleta de dados foi efetivada por meio de questionários sobre os tópicos: melhoria da aprendizagem com E-PELS, eficiência em relação ao método tradicional indiferente ao nível de leitura do aluno. Os resultados obtidos mostraram que o método proposto, apoiado pela tecnologia, proporcionou um melhor desempenho quanto à compreensão leitora quando 
comparado a métodos tradicionais. A pesquisa aqui proposta assemelha-se a este estudo em alguns aspectos. Todavia, enfoca a leitura com base na ferramenta de mineração de texto e discute outros aspectos sobre seu uso, por exemplo: interação entre alunos, leitura de textos extensos, inovação de ideias e suporte para o professor.

Em relação à escrita, Luu e Freeman (2011) realizaram uma investigação sobre o desenvolvimento da pré-escrita e da escrita apoiado em mapas conceituais. Da mesma forma, os autores Feng et al. (1999) entendem que mapas conceituais podem tornar a aprendizagem mais fácil, rápida e agradável. Os passos propostos para o uso dos mapas como apoio à leitura e escrita são: decidir o tema, considerar ideias relacionadas, selecionar palavras e frases que focam o tópico geral, conectar as palavras e frases com as linhas de referência e de relação. Após, os autores sugerem que seja iniciada a escrita do texto com o apoio da representação visual do mapa conceitual. O trabalho de Luu e Freeman (2011) apresenta pesquisa realizada em cursos de inglês em Taiwan com estudantes de todos os níveis. Os resultados apontaram que alunos de nível avançado tiveram melhor desempenho no uso de mapa construído individualmente. Já os níveis iniciais e intermediários obtiveram melhores resultados com o uso coletivo de mapas conceituais.

Além dos estudos acima descritos, outros abordam o tema de forma teórica sem a implicação da prática. A maior parte destes estudos trata somente do desenvolvimento da leitura e da escrita, e não consideram a autoria neste processo. Tal fato destaca a relevância da pesquisa aqui proposta, visto que a atual possibilidade de acesso rápido a conteúdos prontos tem deixado a noção de autoria em situação marginal.

\section{Descrição do Estudo Realizado}

O estudo desenvolvido foi baseado em dois cursos de extensão oferecidos na modalidade semi-presencial para professores de Graduação e Pós-Graduação, bem como para agentes educacionais do Departamento Estadual de Trânsito de Porto Alegre (DETRAN). Esses últimos atuam como formadores em cursos e palestras oferecidos para gestores e professores em instituições educacionais no Rio Grande do Sul. No total, foram 22 participantes.

O interesse deste público estava na apropriação de recursos digitais que pudessem potencializar as práticas pedagógicas com foco no trabalho coletivo, bem como buscar apoio para o processo de mediação dessas práticas. Para o desenvolvimento da proposta, o curso utilizou como ferramentas de apoio o Editor de Texto Coletivo ${ }^{2}$ (ETC) e a ferramenta Sobek. 0 ETC é um editor de domínio público, que proporciona espaço para escrita de textos coletivos de forma online. Além da área de edição, ele dispõe, entre outras, de funcionalidades que apoiam a conversação entre os autores para que possam discutir e negociar a construção textual. Para tanto, estão disponíveis as ferramentas fórum, comentários e comunicador (ferramenta para comunicação síncrona). Também estão disponíveis recursos para gerenciamento de grupos, de

\footnotetext{
${ }^{2}$ Ferramenta de edição de texto online disponível em: http://www. nuted.ufrgs.br/etc2/.
} 
textos e de arquivos; todavia, não serão descritas aqui por não serem o foco neste estudo. No estudo realizado, o ETC serviu de suporte para comunicação, disponibilização de material educacional e, principalmente, para produção textual. Já o Sobek, acessado a partir de um botão disponível na área de edição no ETC, foi utilizado para minerar os textos produzidos e extrair deles os principais conceitos.

Ambos os cursos foram desenvolvidos em quatro aulas, sendo duas presenciais e duas à distância, totalizando 30 horas. No período entre as aulas, as discussões e o desenvolvimento das atividades foram mediados pelas ferramentas de comunicação disponíveis no ETC. A avaliação considerou a participação nas aulas presenciais e à distância, realização e qualidade das atividades coletivas e apresentação da produção final.

O conteúdo dos cursos tratou de aspectos que envolveram as trocas sociais, o trabalho coletivo, a necessidade de negociação entre as pessoas. O foco foi dado na diversidade dessas relações e como trabalhar isso no contexto educacional mediado pela tecnologia. O principal desafio dos participantes foi a construção de um artigo coletivo no próprio ETC com o tema: Tecnologia para potencializar a troca interindividual. As referências teóricas disponibilizadas aos alunos estavam em forma de grafo, gerados pela ferramenta Sobek. A partir desses grafos, os participantes produziram suas próprias escritas e, com base nelas, é que se apoiou a análise deste estudo. A intenção foi verificar se, ao invés de haver somente a reprodução de ideias inicialmente postas, os participantes conseguiriam desenvolver textos com elementos novos que também trouxessem um pouco de suas experiências e realidades. Assim, o objetivo deste estudo foi verificar se o material de apoio, disponibilizado por meio de grafos, mostrava-se útil e eficiente para o desenvolvimento do processo de leitura/escrita autoral. O grafo apresenta e relaciona os principais conceitos tratados em um texto, neste caso, o tema tratava sobre o uso das tecnologias na educação. Exemplo de um dos grafos acessados pelos participantes pode ser visto na Figura 1.

Figura 1 - Grafo Extraído de Texto Disponibilizado aos Participantes

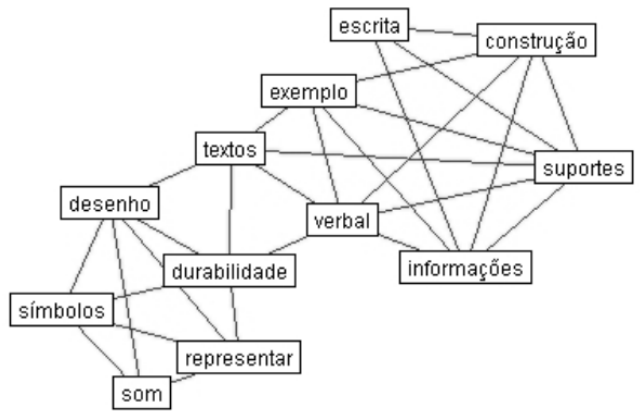

Fonte: Elaborado pelos próprios autores

Após disponibilizar o grafo para leitura, o estudo concentrou-se em identificar a contribuição da ferramenta Sobek no processo de desenvolvimento de leitura e escrita autoral. Para tanto, optou-se por uma abordagem qualitativa na qual os dados coletados no experimento foram analisados e comparados com padrões existentes para a aferição de 
autoria, de acordo com pressupostos apontados por Flick (2009, p. 91), para quem a pesquisa qualitativa "[...] não se limita a concluir e confirmar o que se espera que seja o resultado, e sim produzir novas ideias e formas de ver as coisas e as pessoas estudadas".

A intenção da pesquisa aqui realizada foi identificar marcas de autoria em textos produzidos coletivamente pelos alunos a partir dos grafos gerados pela ferramenta. Segundo Pêcheux (1998), ocupa-se a posição de autor ao agir na produção de sentido. Assim, um texto constituído somente por conceitos é um mote para a produção autoral.

A partir da fundamentação teórica destacada neste estudo, foram criadas as seguintes categorias de análise: pronomes pessoais de 1o pessoa, inclusão de informações diferenciadas e paráfrase. Cada uma destas categorias é detalhada a seguir.

\subsection{Categorização e Análise dos Dados}

Esta seção faz a relação entre os dados analisados e coletados ao longo dos cursos de extensão e sustenta a análise a partir dos referenciais teóricos que serviram de suporte para o estudo.

\subsubsection{Categoria: Pronomes Pessoais}

Tfouni (2009) defende que a autoria é entendida como uma posição discursiva do sujeito construída a partir da aproximação e o distanciamento das palavras do outro. Possenti (2003) enfatiza que este posicionamento do sujeito também pode se mostrar por meio de uma assinatura pessoal ao final do discurso ou por meio de identificação com pronomes pessoais como eu e nós no decorrer do texto. Diante disso, este estudo estabelece, como uma categoria de análise, o encontro de pronomes pessoais em razão de apontarem sinais de autoria.

Nos textos analisados, encontrou-se a preferência pelo uso constante da $1^{\text {a }}$ pessoa do plural, nós como identificação do pensamento das pessoas do grupo, ou seja, como forma de assinatura e responsabilização. Exemplos dessa aplicação podem, por exemplo, ser verificados nos seguintes extratos:

O Grupo A, na categoria Pronomes Pessoais fez uso constante da 1a pessoa, afirmando pensamentos e ações que podem ser notados na oração a seguir:

Neste contexto, precisamos buscar a participação dos professores, principalmente do NDE, juntamente com o coordenador do curso para que todos possam através das relações interpessoais e construção de texto coletivo, participar e auxiliar na construção do PPC. (GRUPO A).

Também o GRUPO B posicionou-se mediante as informações expostas ao usar a 1a pessoa do plural para mostrar as escolhas feitas:

Por isso, elencamos, neste artigo, algumas habilidades que o tutor precisa desenvolver, tais como: escrita objetiva e clara, empatia, descentramento, reflexão sobre si. (GRUPO B).

Ainda na busca de elementos que identificam a presença do autor no texto, Pêcheux (1998) afirma que deve haver retroação na produção de sentido, como a comparação de uma ideia 
nova com outra já existente no contexto histórico do autor, ou seja, a autoria também se constitui por meio de termos que indicam posse de um contexto, de uma situação. O pronome nossa encontrado em diferentes trechos do texto do GRUPO C pode materializar esta tentativa, como vemos:

As tecnologias, hoje, permitem uma gama de interatividade talvez impensada há até pouco tempo. Até nossa própria alfabetização dever passar a ser mais digital. (GRUPO C).

[...] na nossa primeira experiência em um curso piloto sobre educação a distância para os próprios colegas de setor não foi diferente. (GRUPO C).

Usar formas encapsuladas de ideias, como cópias de textos ou como indeterminação do sujeito, é uma forma de anulação da autoria, já que o autor refugia-se por meio da língua do outro, seja repetindo apenas as palavras do outro ou apagando-se do texto por meio de estruturas sintáticas impessoais. Ao contrário disto, vê-se o posicionamento do autor nos trechos seguintes:

E, no intuito de driblar esses fundamentos práticos, tentam, de forma inócua, informatizar aulas estruturadas de modo tradicional, o que, em nosso entendimento, potencializa o maior conflito da relação... (GRUPO D).

Comumente, quando temos alguma dúvida, escutamos sugestões do tipo: "joga no Google", "procura no São Google"... (GRUPO D).

Também ao considerar um termo $X$, deixa-se de considerar outro termo $Y$, o que não constitui meramente uma escolha técnica. O uso de determinados termos ressalta certas ideias e as legitima, ao mesmo tempo em que apaga outras.

A autoria, desta forma, está no processo de atribuição, responsabilização e enunciação de um texto ou de uma obra. Logo, nota-se que houve a demonstração da responsabilidade sobre os termos que reforçam a assinatura do sujeito.

A escrita em primeira pessoa caracteriza uma marca linguística da autoria, pois os autores incluem informações que estão relacionadas às suas expectativas, experiências, ideologias, entre outros aspectos. Em vista disso, chamam para si a responsabilidade das afirmações e das opiniões enunciadas no texto, assim como, constroem informações diferenciadas, como se vê nos extratos destacados.

Por fim, na maioria das situações, não houve a preocupação formal e encapsulada na construção gramatico-pronominal do texto, o que seria uma forma de alienar a autoria. Aliás, encontra-se constante pessoalidade na escrita, por meio de pronomes pessoais e possessivos de primeira pessoa.

\subsubsection{Categoria: Paráfrase}

A atividade de modificação e de reconstrução do texto do outro, ao contrário do que se pensa, também pode ser um sinal de autoria. A paráfrase, no contexto deste estudo, é o processo de interligação entre conceitos gerados pelo grafo, no qual existe a necessidade de preenchimento das lacunas, de agrupamento ou reagrupamento de ideias para que se constitua a estrutura textual coesa. Segundo Bakthin (1989), não há palavra que seja a primeira ou a 
última, e não há limites para o contexto dialógico. Em razão disso, encontram-se nos discursos analisados, muitos outros discursos que colaboram na progressão textual, sem Ihes retirar o caráter autoral, uma vez que estas ideias passam por uma seleção ideológica até chegarem a fazer parte de outro texto.

Forma-se assim, um conjunto de enunciados ditos por um terceiro e reditos pelo autor de modo próprio. Em suma, segundo Fuchs (1982), o termo paráfrase é a atividade de reformulação de textos, sempre partindo de um texto-base que pode estar ou não assinado.

Os excertos a seguir mostram a combinação entre os conceitos retirados do grafo e o aproveitamento de vozes de outros, Bakthin (1989), para dar progressão a um novo texto:

Consideram-se regras tudo aquilo que faz referência às normas/normatizações em geral, sejam regras gramaticais, morais e/ou jurídicas, estando as mesmas presentes em toda a sociedade, trazendo para o debate uma certa consciência de obrigação entre dois indivíduos, mas esta pode estar calcada no respeito unilateral ou mútuo. (GRUPO A)

O professor deve ter a tecnologia como aliada no processo ensino-aprendizagem. O estudante é o centro e a escola é apenas mais um lugar onde ele busca o conhecimento. (GRUPO F)

Nesse contexto, o tutor precisa desenvolver habilidades de comunicação, especialmente a escrita por ser ela a principal ferramenta de comunicação em EAD. É imprescindível explorar ao máximo esta capacidade. (GRUPO C)

Os exemplos e situações supracitados compõem um dizer peculiar a ponto de revelar idiossincrasias suficientes para caracterizar o texto como único, ou melhor, como fruto de um processo autoral.

Outra forma de paráfrase é a utilização da multiplicidade de sentidos que podem ser rememorados em uma forma nova, em um contexto novo, levando-o a adquirir outros significados. Essas são conhecidas como citações diretas ou indiretas. Segundo Tfouni (2009), por meio de citações, o sujeito realiza a tarefa de analista, retomando enunciados já proferidos e amarrando-os com outras ideias, no caso, conceitos advindos do grafo, conforme verificamos em:

[...] a compreensão do processo de ensino-aprendizagem a partir de uma concepção construtivista interacionista, embasada na perspectiva Piagetiana $(1973,1983)$, implica no entendimento de que a aprendizagem é um processo ao mesmo tempo individual e coletivo, onde o conhecimento não está no sujeito nem no objeto, sendo uma construção individual que emana da interação do sujeito com o seu meio. (GRUPO B)

Parafraseando o autor, a apropriação das tecnologias pelas escolas segue três etapas. (GRUPO H)

Portanto, não há nada morto, de maneira absoluta, visto que ideias que são parafraseadas sofrem adaptações às outras ideias e ao contexto. Praticam, assim, dupla ressignificação: sobre si e sobre o texto, demarcando a autoria na construção dos textos a partir dos grafos.

\subsubsection{Categoria: Informações Novas}

Por fim, na categoria Informações Novas, os indícios de autoria também podem ser percebidos ao serem incluídas informações distintas das previsíveis pela temática contextual, 
causando certo grau de surpresa e de singularidade. Nesse sentido, percebe-se que o tema e as informações centrais do texto que advêm do grafo podem influenciar na liberdade de escolha sobre quais informações acrescentar, conforme os exemplos a seguir, nos quais a maior parte das reflexões foi feita como forma de resolução de situações-problema do contexto educacional dos autores.

Já com o cronograma das etapas do projeto estabelecidas pelo professor e entregue aos alunos, o acompanhamento do ensino a distância começa a partir da socialização para definição do tema de pesquisa [...] (Grupo G).

Indícios de autoria também podem ser selecionados mais ou menos pessoalmente, o que poderia dar a entender que se trata de um saber pessoal, posto a funcionar segundo o critério do gosto ou da necessidade. Nestes trechos, houve o aproveitamento do conhecimento da realidade do professor, inspirado nos colegas de trabalho, ao mesmo tempo que a tentativa de solução direcionada e singular para estes problemas.

Da mesma forma, precisamos utilizar todos os recursos que as TIC's nos proporcionam para nos auxiliar na gestão e coordenação dos cursos superiores. Hoje, a grande maioria dos professores do curso atuam no mercado de trabalho durante o dia, e a noite aplicam seus conhecimentos e experiências em sala de aula, como professores. (Grupo A).

[...] Esta é a realidade de um dos universos existentes no ensino técnico, enquanto, do outro lado, existe o aluno que não tem computador em casa e que, no seu ambiente de trabalho não tem acesso à tecnologias. (Grupo F).

Não é oferecendo uma aula "livre" no laboratório de informática ou solicitando um trabalho de pesquisa na internet, que o educador estará possibilitando aos alunos um real e interativo ambiente virtual de aprendizagem. (Grupo E)

O sujeito inscreve sua presença no enunciado, o que pode ser feito de maneira mais ou menos visível e nos permite propor que, ao fazê-lo, pode se mover em um espaço de certa singularidade. Nestes casos, mesmo submetido a coerções históricas e enunciativas, o sujeito desempenha um papel ativo que faz significar o que não estava dito, conforme Geraldi (1985).

Por fim, a autoria pode ser percebida na busca pela palavra a ser traduzida pelas particularidades do autor reveladas no texto, informações que não são previsíveis, mas que determinam e enriquecem o jogo entre o já dito e o novo. Os recursos, por exemplo, de dar nomes para as áreas de ensino, para os níveis, citar dificuldades, fornecer ilustrações, como dito em alguns dos exemplos destacados, também são formas de se autorar e evitar a impessoalidade.

Conforme os resultados de trabalhos anteriores a este, Klemann, Lorenzatti e Reategui (2009) e Macedo (2010), o grafo mostrou-se capaz de ter estreita relação com a estrutura e o conteúdo do texto de que foi extraído e também se mostrou capaz de identificar a qualidade na produção escrita dos estudantes. Já no presente estudo, nota-se a possibilidade de colaborar no desenvolvimento da leitura e da escrita autoral.

O fato de o grafo utilizar apenas nodos e arestas, os quais se apresentam em tamanhos diferentes conforme sua notoriedade no texto, impõe ao leitor-escritor completar as lacunas entre um nodo e outro, tendo de usar para isso as arestas como guias de conexão e suas vivências particulares como preenchimento para o conteúdo. Assim, os grupos viram-se 
convidados a parafrasear o grafo e incluir informações pessoais para procederem à leitura e a escrita, neste processo. Além disso, fizeram escolhas gramatico-pronominais para que houvesse interpretabilidade em seu discurso, ou seja, a partir dos sinais ressaltados pelo grafo, construíram textos marcados por suas leituras, interações e experiências, marcando assim um processo autoral.

Assumir-se como autor significa textualizar seu discurso, compor um dizer todo seu, inteiramente peculiar, no que tange à materialidade linguística mobilizada para tal. Assim, no momento em que os grupos reinventaram a realidade, parafraseando-a com suas particularidades estavam imprimindo diferenças em seu texto a ponto de levar seus leitores a enxergarem particularidades suficientes para caracterizá-los como autor. Ou seja, quanto mais um indivíduo se apropria da competência autoral, mais ele deixa entrever em seus textos as marcas de si, da sua subjetividade, traços indiciadores de suas escolhas e preferências linguístico-discursivas.

A utilização de representações gráficas para apoio à escrita tem apresentado resultados positivos em diferentes estudos, auxiliando os aprendizes a segmentar os tópicos que devem ser contemplados em seus textos e apoiando-os na estruturação de sua escrita (BEISSNER; JONASSEN; GRABOWSKI, 1994, MOHAMED; OMAR, 2008). Os resultados da pesquisa apresentada neste artigo demonstraram que a utilização do método proposto teve um papel importante na estruturação do processo de escrita dos textos, além de promover a escrita autoral.

Ao invés de iniciarem com uma página em branco, os alunos começaram suas produções a partir de ideias e reflexões propostas pelos grafos. Ruddell (2001) ratifica o interesse neste modelo de estratégia de escrita, enfatizando a importância de ferramentas que possibilitem aos alunos ilustrar suas construções e organização do conhecimento, permitindo que visualizem as principais ideias a serem contempladas em suas produções e como estas se conectam.

\section{Conclusão}

Este trabalho apresentou uma análise sobre a contribuição da tecnologia de mineração de texto no processo de letramento e autoria. A análise das produções textuais de 22 alunos de dois cursos de extensão permitiu concluir que a ferramenta e estratégias propostas contribuíram para o desenvolvimento de uma escrita autoral pelos participantes da pesquisa.

Vale ressaltar que, durante a produção textual, o grafo foi a peça central para a escrita do texto, tanto para orientar os alunos sobre quais termos e ideias deveriam aparecer no artigo, como para auxiliá-los a identificar quais relações de informações deveriam estar presentes nas suas produções. Por meio dos textos produzidos, percebe-se que os participantes se empenharam em utilizar os termos apresentados no grafo de forma condizente com seus significados. Contudo, também houve empenho para aproximar/adaptar as informações do grafo à realidade de cada grupo. $O$ fato de não partirem de um texto linear, além de não afetar a interpretação, ainda os motivou a se inserirem no texto por meio da escrita em primeira pessoa, da seleção de ideias existentes em seu contexto educacional e também do enlace com 
suas necessidades e situações de trabalho. Como resultado, pode-se afirmar que os grupos apresentaram indícios de autoria em suas produções textuais.

No que tange à comparação da pesquisa aqui apresentada com outras similares, a principal diferença que pode ser destacada é que, ao invés de discutir o uso da tecnologia para apoio à leitura e escrita de maneira mais ampla, este trabalho focou na utilização das tecnologias de mineração e edição de texto como forma de apoio à leitura e escrita autoral. Por muito tempo os pesquisadores têm investigado como representações não linguísticas podem apoiar os estudantes em atividades de leitura e escrita (MARZANO; PICKERING; POLLOCK, 2001, HYERLE, 2009). Aqui, nosso foco foi abordar ferramentas e práticas que pudessem apoiar a escrita autoral, mais precisamente.

As crescentes aplicações da ferramenta Sobek em contextos educacionais têm favorecido seu aprimoramento e seu emprego em diferentes situações. Assim, vê-se como possibilidade de pesquisas futuras o acompanhamento dos estudantes por períodos mais longos para investigar de que maneira se apropriam da tecnologia e como as utilizam em suas práticas de leitura e escrita.

\section{Referências}

ANDERSON, R. C.; PEARSON, P. D. A Schema-theoretic View of Basic Processes in Reading Comprehension. In: CARREL, P. L.; DEVINE, J.; ESKEY, D. E. (Ed.). Interactive Approaches to Second Language Reading. $8^{\text {th }}$ ed. Cambridge: Cambridge University Press, 1998. P. 37-55.

ASSOLINI, F. E. P. Interpretação e Letramento: os pilares de sustentação da autoria. 2003. Tese (Doutorado)-Faculdade de Filosofia, Ciências e Letras de Ribeirão Preto, Universidade de São Paulo, Ribeirão Preto, 2003.

BAKHTIN, M. Os Generos do Discurso. In: BAKHTIN, M. Estética da Criação Verbal. São Paulo: Martins Fontes, 2001. P. 277-327.

BEISSNER, K.; JONASSEN, D. H.; GRABOWSKI, B. L. Using and Selecting Graphic Techniques to Acquire Structural Knowledge. Performance Improvement Quarterly, v. 7, n. 34, p. 20-38, 1994.

BRONCKART, J. P. Atividades de Linguagem, Textos e Discursos: por um interacionismo sócio-discursivo. São Paulo: EDUC, 1999.

CASTELLS, M. A Sociedade em Rede. São Paulo: Paz e Terra, 1999.

CHANG, K. E.; SUNG, Y. T. The Effect of Concept Mapping to Enhance Text Comprehension and Summarization. The Journal of Experimental Education, v. 71, n. 1, p. 5-23, 2002.

FENG, C. et al. Marked-up Text Mining for Error Analysis in a Networked Writing Classroom. In: INTERNATI ONAL CONFERENCE ON COMPUTER IN EDUCATION (ICCE 99), 7., 1999, Chiba, JP. Proceedings. Tokyo: ICCE, 1999. V.1, p. 378-385.

FERRER, F.; BELVÍS, E.; PÀMIES, J. Tablet PCs, Academic Results and Educational Inequalities. Computers and Education, v. 56, n. 1, p. 280-288, 2011.

FLICK, U. Introdução à Pesquisa Qualitativa. São Paulo: Artmed, 1995.

FLICK, U. Qualidade na Pesquisa Qualitativa: desenho da pesquisa qualitativa. Tradução: Roberto Costa. Porto Alegre: Artmed, 2009.

FUCHS, C. La Paraphrase. Paris: Press Universitaires de France, 1982.

GERALDI, J. W. Operadores de Argumentação e Diálogo. Cadernos de Estudos Linguísticos, Campinas, v. 9, p. 143-157, 1985. 
GINZBURG, C. Sinais: raízes de um paradigma indiciário. In: GINZBURG, C. Mitos, Emblemas e Sinais: morfologia e história. Tradução Frederico Carottti. São Paulo: Companhia das Letras, 1980. P. 143-179.

HYERLE, D. N. Visual Tools for Transforming Information into Knowledge. Thousand Oaks: Corwin Press, 2009.

JENNER, J. A Bridge to Reading and Writing Literacy: developing oral language skills in young children. Pacific Educator, v. 2, n. 1, p. 7-8, 2003.

KLEIMAN, A. Aspectos Cognitivos da Leitura. Campinas: Pontes, 1989.

KLEMANN, M.; LORENZATTI, A.; REATEGUI, E. O Emprego da Ferramenta de Mineração de Textos Sobek Como Apoio à Produção Textual. In: SIMPÓSIO BRASILEIRO DE INFORMÁTICA NA EDUCAÇÃO, 20., 2009, Florianópolis. Anais. Florianópolis: SBC, 2009. P. 1-10.

LUU, K.; FREEMAN, J. G. An Analysis of the Relationship Between Information and Communication Technology (ICT) and Scientific Literacy in Canada and Australia. Computers and Education, v. 56, n. 4, p. 1072-1082, 2011.

MACEDO, A. Rede de Conceitos: uma ferramenta para contribuir com a prática pedagógica no acompanhamento da produção textual coletiva. 2010. Tese (Doutorado)-Progama de Pós Graduação em Informática na Educação, Universidade Federal do Rio Grande do Sul, Porto Alegre, 2010.

MAKREHCHI, M.; KAMEL, M. Automatic Extraction of Domain-Specific Stopwords from Labeled Documents. In: EUROPEAN CONFERENCE ON IR RESEARCH, 30., 2008, Glasgow. Proceedings. Berlin: Springer, 2008. P. 222-233.

MARASCHIN, C.; AXT, M. Acoplamento Tecnológico e Cognição. In: VIGNERON, J.; OLIVEIRA, V. B. de (Org. ). Sala de Aula e Tecnologias. São Bernardo do Campo: Universidade Metodista de São Paulo, 2005. P. 39-51.

MARCUSCHI, L. A.; XAVIER, A. C. Hipertexto e Gêneros Digitais: novas formas de construção do sentido. 2. ed. Rio de Janeiro: Lucerna, 2005.

MARZANO, R. J.; PICKERING, D. J.; POLLOCK, J. E. Classroom Instruction that Works: research-based strategies for increasing student achievement. Alexandria, USA: Association for Supervision and Curriculum Development, 2001.

MOHAMED, W. A. W.; OMAR, B. Using Concept Map to Facilitate Writing Assignment. In: INTERNATIONAL CONFERENCE ON CONCEPT MAPPI NG, 3., 2008, Tallin, EE. Proceedings. Tallin, EE: IHMC, 2008. P. 172176.

ORGANIZATION FOR ECONOMIC COOPERATION AND DEVELOPMENT. PISA 2006: science competencies for tomorrow's world. Paris: OECD, 2006.

ORGANIZATION FOR ECONOMIC COOPERATION AND DEVELOPMENT. PISA Results 2012: what students know and can do: student performance in reading, mathematics and science. Paris: OECD, 2012.

ORLANDI, E. P. Discurso e Leitura. São Paulo: Cortez, 1988.

PÊCHEUX, M. Semântica e Discurso: uma crítica à afirmação do óbvio. Campinas: Unicamp, 1995.

PÊCHEUX, M. Análise Automática do Discurso. In: GADET, F; HAK, T. (Org.). Por uma Análise Automática do Discurso: uma introdução à obra de Michael Pêcheux. Campinas: Unicamp, 1998. P. 61-161.

PETKO, D. Teachers' Pedagogical Beliefs and their Use of Digital Media in Classrooms: sharpening the focus of the 'will, skill, tool' model and integrating teachers' constructivist orientations. Computers and Education, v. 58, n. 4 , p. 1351-1359, 2012

PONCE, H. R.; LÓPEZ, M. J.; MAYER, R. E. Instructional Effectiveness of a Computer: supported program for teaching reading comprehension strategies. Computers and Education, v. 59, n. 4, p. 1170-1183, 2012.

POSSENTI, S. Enunciação, Autoria, Estilo. Revista da FAEEBA, n. 15, p. 15-21, 2001.

POSSENTI, S. Observações Esparsas sobre Discurso e Texto. Cadernos de Estudos Linguísticos, Campinas, v. 44, n. 1, p. 211-222, 2003.

REATEGUI, E. et al. Sobek: a text mining tool for educational applications. In: IEEE INTERNATIONAL CONFERENCE ON DATA MINING, 2011, Las Vegas. Proceedings. Las Vegas: IEEE. 2011. P. 59-64. 
REATEGUI, E.; KLEMANN, M.; FINCO, M. D. Using a Text Mining Tool to Support Text Summarization. In: IEEE INTERNATI ONAL CONFERENCE ON ADVANCED LEARNING TECHNOLOGIES (ICALT), 12., 2012, Rome. Proceedings. Rome: IEEE. 2012. P. 607-609.

RIZZO, G. Fundamentos e Metodologia da Alfabetização: método natural. 4. ed. Rio de Janeiro: Francisco Alves, 1986.

RUDDELL, M. R. Teaching Content Reading and Writing. 3. ed. New York: J ohn Wiley \& Sons, 2001.

SERCE. Second Regional Comparative and Exploratory Study: student achievement in latin america and the caribbean. Santiago: OREALC/UNESCO, 2008. Disponível em:

<http://unesdoc. unesco.org/images/0016/001610/161045E.pdf>. Acesso em: 19 maio 2015.

SOARES, M. B. Letramento: um tema em três gêneros. Belo Horizonte: Autêntica, 1998.

TFOUNI, L. L. V. Múltiplas Faces da Autoria. Ijuí: UNIJUÍ, 2009.

TFOUNI, L. L. V.; BARTIJOTTO, J. A Autoria na Descrição do Ato Infracional. Linguagem em (Dis)curso, v. 15, n. 1, p. 137-147, 2015.

VILLALÓN, J. et al. Glosser: enhanced feedback for student writing tasks. In: IEEE INTERNATIONAL CONFERENCE ON ADVANCED LEARNING TECHNOLOGIES, 8., 2008, Santander, ES. Proceedings. Santander, ES: IEEE, 2008. P. 454-458.

WARSCHAUER, M. Laptops and Literacy: learning in the wireless classroom. New York: Teachers College, 2006.

WEI, C. W. et al. Construction of Reading Guidance Mechanism on e-Book Reader Applications for Improving Learners' English Comprehension Capabilities. In: IEEE INTERNATIONAL CONFERENCE ON ADVANCED LEARNING TECHNOLOGIES, (ICALT), 12., 2012, Rome. Proceedings. Rome: IEEE, 2012. $170-172$.

Recebido em 19 de maio de 2015

Aprovado para publicação em 21 de fevereiro de 2016

\section{Alexandra Lorandi Macedo}

Universidade Federal do Rio Grande do Sul - UFRGS, Porto Alegre, Brasil, alorandimacedo@gmail.com

Francieli Luísa Gracioli

Universidade Federal do Rio Grande do Sul - UFRGS, Porto Alegre, Brasil, francieligracioli@gmail.com

Eliseo Berni Reategui

Universidade Federal do Rio Grande do Sul - UFRGS, Porto Alegre, Brasil, eliseoreategui@gmail.com

Patricia Alejandra Behar

Universidade Federal do Rio Grande do Sul - UFRGS, Porto Alegre, Brasil, pbehar@terra.com.br

Vinicius Hartmann Ferreira

Universidade Federal do Rio Grande do Sul - UFRGS, Porto Alegre, Brasil, vinihf@gmail.com 